\title{
LOS DERECHOS FUNDAMENTALES MÁS ALLÁ DE LOS DERECHOS FUNDAMENTALES. NOTAS PARA ENSEÑAR DERECHO CONSTITUCIONAL
}

Fundamental rights beyond fundamental rights. Notes for teaching Constitutional Law

Recibido: 13 de noviembre de 2020

Aceptado: 12 de julio de 2021

Ignacio Álvarez Rodríguez

Profesor Contratado Doctor (E.R.I) de Derecho Constitucional

ialvarez1@ucm.es

Universidad Complutense de Madrid

\section{RESUMEN}

El presente artículo científico pretende demostrar que el contenido de los derechos fundamentales, entendidos estos en su vertiente internacional y más concretamente convencional en interpretación dada por el Tribunal Europeo de Derechos Humanos, impregna (o debería impregnar) la actuación e incluso esencia de diversos poderes públicos institucionales ("parte orgánica" de la Constitución), más allá de los análisis tradicionales que circunscriben su fuerza de obligar sólo en los derechos fundamentales ("parte dogmática" de la Constitución).

\section{PALABRAS CLAVE}

Derecho Constitucional, Enseñanza Universitaria, Convenio Europeo de Derechos Humanos, Tribunal Europeo de Derechos Humanos.

\begin{abstract}
This scientific article aims to demonstrate that the content of fundamental rights, understood in their international and more specifically conventional perspective in interpretation given by the European Court of Human Rights, permeates (or should permeate) the actions and even the essence of various public powers. institutional ("organic part" of the Constitution), beyond the traditional analyzes that circumscribe its force of binding only on fundamental rights ("dogmatic part" of the Constitution).
\end{abstract}

\section{KEYWORDS}

Constitutional Law, University Teaching, European Convention on Human Rights, European Court of Human Rights 
Sumario: 1. Introducción. 2. Constitución, sistema electoral y partidos políticos. 3. Constitución y parte orgánica. 3.1. Corona. 3.2. Cortes Generales. 3.3. Gobierno. 3.4. Poder Judicial. 4. Constitución y Economía y Hacienda. 5. Constitución y Organización Territorial del Estado. 6. Conclusiones. 7. Bibliografía.

\section{Introducción.}

La hipótesis de partida de este trabajo es intentar demostrar cómo el contenido de los derechos fundamentales, entendidos estos en su vertiente internacional y más concretamente convencional en interpretación dada por el Tribunal Europeo de Derechos Humanos, incide en buena parte de la actuación e incluso esencia de diversos poderes públicos institucionales que forman parte de la enseñanza clásica del Derecho Constitucional y no sólo en la parte específica que dicha disciplina dedica a los derechos fundamentales. ${ }^{1}$

Esa idea se va a transmitir mediante una selección de sentencias del Tribunal Europeo de Derechos Humanos. ${ }^{2}$ A través de las mismas se puede observar cómo un tribunal internacional como el TEDH, órgano jurisdiccional prestigioso aunque lógicamente no exento de críticas, resuelve el litigio procesal sobre uno o varios derechos fundamentales concretos pero, al hacerlo, está afectando también de alguna forma a otras materias que tienen que ver con cuestiones relacionadas con el sistema electoral y el rol de los partidos políticos; con el modelo de descentralización político-territorial de cada país; con la que solemos llamar "la parte orgánica" (por ejemplo, Jefatura del Estado, Parlamento, Gobierno, Poder Judicial); y hasta con las disposiciones que se refieren a cuestiones que tienen que ver frontalmente con Economía y Hacienda. ${ }^{3}$

En definitiva, con este repaso a la jurisprudencia de Estrasburgo se intentará demostrar cómo la enseñanza del Derecho Constitucional en pleno siglo XXI no puede limitarse a explicar cómo afecta el Convenio Europeo de Derechos Humanos a la parte dogmática de la Constitución (derechos fundamentales) sino cómo lo hace, desde la transversalidad más objetiva, a la parte orgánica (órganos, instituciones). Dicho con otras palabras: los derechos como eje vertebrador que va más allá de los propios derechos para impregnar el ordenamiento constitucional in toto. ${ }^{4}$

\footnotetext{
${ }^{1}$ Algunos sectores académicos creen que se puede hablar de constitucionalismo global o mundial siempre que este tenga en los derechos fundamentales como su principal eje gravitatorio. Véase FERRAJOLI, L; Constitucionalismo más allá del Estado, Trotta, Madrid, 2018, p. 25 y ss; y varias de las contribuciones compiladas en ELÓSEGUI ITXASO, M; MORTE GÓMEZ, C; MENGUAL I MALLOL, A.M; y CANO PALOMARES, G (coords); Construyendo los derechos humanos en Estrasburgo. El Tribunal Europeo de Derechos Humanos y el Consejo de Europa, Tirant lo Blanch, Valencia, 2020.

${ }^{2}$ Para poder entender el sistema del Convenio y la jurisprudencia del Tribunal puede verse LÓPEZ GUERRA, L; El Convenio Europeo de Derechos Humanos según la jurisprudencia del Tribunal de Estrasburgo, Tirant lo Blanch, Valencia, 2021; ÁLVAREZ RODRÍGUEZ, I; Brechas Convencionales en España. Un reto constitucional del siglo XXI, Aranzadi, Cizur Menor, 2020; CASADEVALL, J; El Tribunal de Estrasburgo. Una Inmersión Rápida, Tibidabo Ediciones, Barcelona, 2019; GARCÍA ROCA, J; La transformación constitucional del Convenio Europeo de Derechos Humanos, Aranzadi, Cizur Menor, 2019; y VVAA; "El Tribunal Europeo de Derechos Humanos", Teoría y Realidad Constitucional, n 42, 2018.

${ }^{3}$ Para un estudio exhaustivo de las implicaciones para el ordenamiento constitucional patrio puede verse MONTESINOS PADILLA, C; La tutela multinivel de los derechos desde una perspectiva jurídicoprocesal, Tirant lo Blanch, Valencia, 2017.

${ }^{4}$ Para el caso del ordenamiento de la Unión Europea puede verse el magnífico análisis de FERRER MARTÍN DE VIDALES, C; "The European integration process. Its effects in the principle of separation of powers set up in Member State's Constitutions", Revista Universitaria Europea, nº 33, 2020, págs. 1758 .
} 


\section{Constitución, sistema electoral y partidos políticos.}

La formación de buena parte de los órganos políticos representativos se conforma mediante los partidos políticos y el sistema electoral. Los unos compiten legítimamente por el poder y llegan a las instituciones mediante las reglas aplicadas por el segundo. Unos y otros tienen una clara impronta nacional y, por ende, sumamente idiosincrática y peculiar que se adapta a las necesidades del país en cuestión. En consecuencia, el TEDH en principio suele emplear el criterio del margen de apreciación nacional, siendo deferente para con los Estados miembros del Convenio.

Sin embargo, el TEDH ha dicho y no pocas veces que existe algo llamado orden público europeo, una democracia convencional, integrada por una serie de reglas y principios que respeten unos mínimos ligados a los derechos y libertades de las personas que están en sus territorios. ${ }^{5}$ Y esta democracia tiene ciertos tintes militantes, cabe recordar. Aunque en España nuestro Tribunal Constitucional ha reiterado que la Constitución de 1978 no exige una adhesión positiva al ordenamiento constitucional, el TEDH ha ido un poco más allá, dejando dicho para quien quiera leerlo que no todo proyecto político subversivo tiene encaje dentro de los márgenes del Convenio. Dada la enjundia del asunto, conviene explicar esto en dos fases diferenciadas. La primera se refiere al sistema electoral y la segunda tratará sobre los partidos políticos propiamente dichos. ${ }^{6}$

Respecto al sistema electoral, huelga decir que estamos ante un complejo entramado de normas, principios e instituciones que responde a las necesidades políticas (a la idiosincrasia política y social, si se prefiere) de cada Estado. Aunque podemos teorizar y tratarlo como algo homogéneo, la realidad es que cada uno responde a la idiosincrasia y a las decisiones (y no decisiones) tomadas en su día por los afectados. Su acusada resistencia al cambio y las funciones que cumple (generar legitimidad, generar gobierno, generar representación) hacen de este la columna vertebral de la democracia. ${ }^{7}$

El TEDH no se ha prodigado apenas en la materia -el margen de apreciación nacional es amplio- aunque cuando lo ha hecho ha arrojado algo de luz sobre las implicaciones que el Convenio tiene para los sistemas de los Estados miembro, en concreto desde la óptica del artículo 3 del Protocolo 1 del Convenio. Y así llegaron las sentencias del Tribunal Europeo de Derechos Humanos en el asunto Yumak y Sadak c. Turquía, primero la de Sala (30/1/2007) y luego la de Gran Sala (8/7/2008), donde confirma el criterio de aquella. Los dos demandantes turcos creían que la barrera electoral del $10 \%$ vulneraba el precepto. Las dos sentencias, haciendo un repaso exhaustivo a la idea de sistema electoral y a los fines que persiguen, basando el análisis comparado en buena parte de los modelos de los Estados miembro del Consejo de Europa y en el Código de Buenas Prácticas de la Comisión de Venecia, concluye que en esta materia existe un amplio margen de apreciación nacional y Turquía no será la excepción. Eso sí, tanto la Sala como la Gran Sala dijeron que la barrera electoral del $10 \%$ era demasiado alta -"la más alta de todos los Estados del Consejo de Europa"- y que debía reducirse (siempre con un exquisito lenguaje diplomático-judicial, como lo muestran las resoluciones de Sala y de Gran Sala). La sentencia de Gran Sala tuvo

\footnotetext{
5 Vid. PINTO DE ALBUQUERQUE, P; "The constitutionalisation of the legal order of the Council of Europe". En MOTOC, I; PINTO DE ALBUQUERQUE, P; y WOJTYCZEK, K (eds); New developments in constitutional law. Essays in honour of András Sajó, Eleven International Publishing, The Hague, The Netherlands, 2018, p. 317 y ss.

${ }^{6}$ Véase el sugerente análisis que realiza el profesor ORTEGA CARCELÉN, M; España en positivo, Servicio de Publicaciones de la Facultad de Derecho de la Universidad Complutense de Madrid, Madrid, 2018.

${ }^{7}$ Para nuestro caso es imprescindible la consulta de GARROTE DE MARCOS, M ${ }^{\mathrm{a}}$; El sistema electoral español. Memoria, balance y cambio, Marcial Pons, Madrid, 2020.
} 
un voto particular suscrito por cuatro magistrados que, justo por ese motivo, por lo alto de la barrera, creían que el precepto se lesionaba.

Respecto a los partidos políticos, huelga decir que la creación, mantenimiento, y desarrollo de un partido político es ejercicio de derechos fundamentales. Respecto al Convenio, el principal artículo que entra en juego es el artículo 10 (libertad de expresión política) y el artículo 11 (derecho de asociación en su vertiente política). ${ }^{8}$ No obstante, desde una perspectiva sistémica quizá no esté de más recordar lo que hay, o puede haber detrás. No es tanto que se analicen los derechos fundamentales relacionados con el normal desenvolvimiento de la función propia de los partidos sino de la inextricable unión que existe entre estos y el sistema democrático. Así, es jurisprudencia reiterada del TEDH que los partidos políticos son un elemento esencial de la democracia en general y de las democracias convencionales en particular, toda vez que el orden público europeo se basa en el pluralismo como valor esencial. ${ }^{9}$

Por eso es especialmente importante recordar que el TEDH ha considerado conforme al Convenio -esto es, no se lesiona ninguno de los derechos antecitados- si se ilegalizan formaciones políticas que tienen como vocación subvertir el orden constitucional del país en cuestión. Esto entronca con una de retos más complejos y más bonitos del Derecho Constitucional de todos los tiempos, como es el asunto de la democracia militante, tal y como Karl Loewenstein defendió a mediados del siglo pasado y tal y como seguimos intentando explicar con toda modestia desde nuestras aulas: que la Constitución no es axiológicamente neutral y que además probablemente no pueda serlo. ${ }^{10}$

No parece que haya muchas dudas acerca de qué se debe hacer si un partido político defienda subvertir el orden demo-constitucional mediante la violencia, directa $\mathrm{o}$ indirectamente. En ese sentido, incurriría en las responsabilidades penales pertinentes, siendo la ilegalización una de las medidas de respuesta. A partir de 2002 quedó claro que la ilegalización iba a tomar un nuevo impulso, con la entrada en vigor de la nueva Ley de Partidos. La ilegalización de Herri Batasuna y de sus diferentes marcas y emblemas a lo largo del tiempo fue sentenciada por el Tribunal Supremo y confirmada por el Tribunal Constitucional, afirmando este que nuestro modelo no exige un modelo de democracia militante, sino que cabe defender lo que políticamente se quiera, siempre y cuando no se haga mediante la violencia. No es una cuestión de medios (libertad total de manifestar cualesquiera ideas) sino de fines (sólo pacíficamente). Así que todos estábamos expectantes por saber cómo acabaría la cosa en Estrasburgo. Y el TEDH, aplicando una jurisprudencia más o menos constante desde el asunto Refah Partisi c. Turquía (2003), estableció en el asunto ANV c. España (2013) que la ilegalización del partido político abertzale no sólo estaba dentro de los márgenes del Convenio, sino que dejó un párrafo que fue incluso más allá que nuestros tribunales. Es el 81 y dice así: "A este respecto, el TEDH recuerda que acaba de reconocer que la injerencia encausada -la ilegalización- respondía a una «necesidad social imperiosa». Los proyectos políticos del partido demandante entran

\footnotetext{
8 Véase los criterios del TEDH actualizados en Vid. ELÓSEGUI ITXASO, M": "El principio de proporcionalidad, la incitación al odio y la libertad de expresión en la reciente Jurisprudencia del Tribunal Europeo de Derechos Humanos: los Casos Stomakhin c. Rusia, Williamson c. Alemania y Pastörs c. Alemania", Revista General de Derecho Europeo, no. 51, 2020, pp. 15-54; y en ROCA FERNÁNDEZ, M.J; "Límites a la libertad de expresión de los políticos. Los casos Féret c. Bélgica y Perinçek c. Suiza", Revista de Derecho Político, no 109, 2020, pp. 345-370.

${ }^{9} \mathrm{El}$ lector que desee profundizar en la cuestión puede ver los diferentes trabajos compilados en MATIA PORTILLA, F.J (dir): Problemas actuales sobre el control de los partidos políticos, Tirant lo Blanch, Valencia, 2016.

${ }^{10}$ Vid. FERNÁNDEZ-MIRANDA, A; y C; Sistema electoral, partidos políticos y Parlamento, Colex, Madrid, 2008 ( $2^{\mathrm{a}}$ edición), p. 45 y ss.
} 
en contradicción con el concepto de «sociedad democrática» y representan un gran peligro para la democracia española, siendo la sanción impuesta al interesado proporcionada al objetivo legitimo perseguido en el sentido del artículo $11 \S 2(\ldots)$. De lo que resulta, que la disolución puede ser considerada «necesaria en una sociedad democrática», particularmente para el mantenimiento de la seguridad pública, la defensa del orden y la protección de los derechos y libertades de terceros, en el sentido del artículo 11 § 2."

Dicho punto de vista se ha visto específicamente apoyado en la decisión de inadmisión del TEDH dictada al hilo del procés. Hablamos del asunto Forcadell $i$ Lluís y otros c. España (7 de mayo de 2019), donde el Tribunal "recuerda que un partido político puede hacer campaña a favor de una modificación de la legislación o de las estructuras jurídicas o constitucionales del Estado siempre que respete dos condiciones: 1) que los medios utilizados a tal fin sean legales y democráticos en todos los aspectos; 2) que la modificación propuesta sea compatible con los principios democráticos fundamentales" (parágrafo 37).

\section{Constitución y parte orgánica.}

En este apartado vamos a intentar demostrar la hipótesis respecto a los órganos constitucionales básicos, especialmente en el influjo de los derechos fundamentales interpretados en clave convencional en el marco de la Jefatura del Estado, de las Cortes Generales, del Gobierno, y del Poder Judicial, respectivamente.

\subsection{Jefatura del Estado}

Decidir la forma de gobierno de un país no es algo que pueda decidir el TEDH. Pero eso no significa que a este le resulte completamente desconocida y ajena las formas de gobiernos en sus sentencias. Por ejemplo, determinadas expresiones manifestadas en torno a algunos Jefes de Estado que fueron sancionadas por las autoridades nacionales, Estrasburgo entendió que eran ejercicio de la libertad de expresión (caso Gutiérrez Suárez, donde ampara a un periodista que ligó a la realeza marroquí con una operación de narcotráfico). E incluso llega a decir literalmente en varias sentencias que tipificar penalmente de forma más grave las ofensas a la Jefatura del Estado no se atiene al espíritu del Convenio (el último ejemplo es el asunto Stern Taulats y Roura Capellera, que involucraba a los Reyes de España). Por ejemplo, en esta última, el parágrafo 57 dice literalmente así: "en materia de insulto contra un Jefe de Estado, el TEDH ya ha declarado que una mayor protección mediante una ley especial en materia de insulto no es, en principio, conforme al espíritu del Convenio (asunto Colombani y otros c. Francia, §§ 6669; asunto Pakdemirli c. Turquía; §§ 51-52, asunto Artun y Güvener c. Turquía, § 31; y asunto Otegi Mondragón c España, §§ 55-56). En efecto, el interés de un Estado en proteger la reputación de su propio Jefe de Estado no puede justificar que se le otorgue a este último un privilegio o una protección especial con respecto al derecho de informar y de expresar opiniones que le conciernen (asunto Otegi Mondragón anteriormente citada $\S$ $55)$ ".

Aplicado al caso concreto, reitera el TEDH que "36: el acto que se reprocha a los demandantes se enmarca en el ámbito de la crítica política, y no personal, de la institución de la monarquía en general y en particular del Reino de España como nación. Esta conclusión se manifiesta claramente al examinar el contexto en el que este acto tuvo lugar. Este se produjo con motivo de la visita institucional del Rey de España a Girona, que fue seguida por una manifestación anti monárquica e independentista que tenía como lema "300 años de Borbones, 100 años combatiendo la ocupación española". Fue después de esta manifestación cuando se produjo una concentración en una plaza de la ciudad donde los demandantes se dirigieron al centro de la misma para dedicarse a la puesta en escena 
que ha resultado en su condena penal, utilizando una fotografía de los Reyes. Esta controvertida puesta en escena se enmarcaba en el ámbito de un debate sobre cuestiones de interés público, a saber la independencia de Cataluña, la forma monárquica del Estado y la crítica al Rey como símbolo de la nación española. Todos estos elementos permiten concluir que no se trataba de un ataque personal dirigido contra el rey de España, que tuviera como objeto menospreciar y vilipendiar a la persona de este último, sino de una crítica a lo que el Rey representa, como Jefe y símbolo del aparato estatal y de las fuerzas que, según los demandantes, habían ocupado Cataluña - lo cual atañe al ámbito de la crítica o disidencia política y corresponde a la expresión de un rechazo de la monarquía como institución.

El TEDH, analizando los tres elementos que sirvieron al TC para condenar por discurso de odio (recurrir al fuego, utilizar una fotografía de grandes dimensiones, y colocarla bocabajo) entiende que se emplearon de forma simbólica, "que tienen una relación clara y evidente con la crítica política concreta expresada por los demandantes, que se dirigía al Estado español y su forma monárquica: la efigie del Rey de España es el símbolo del Rey como Jefe del aparato estatal, como lo muestra el hecho de que se reproduce en las monedas y en los sellos, o situada en los lugares emblemáticos de las instituciones públicas; el recurso al fuego y la colocación de la fotografía bocabajo expresan un rechazo o una negación radical, y estos dos medios se explican como manifestación de una crítica de orden político u otro (ver, en lo que respecta la quema del retrato del Jefe del Estado, el asunto Parti populaire démocratechrétien ( $\left.n^{o} 2\right)$, anteriormente citado); el tamaño de la fotografía parecía dirigida a asegurar la visibilidad del acto en cuestión, que tuvo lugar en una plaza pública. En las circunstancias del presente caso, el TEDH observa que el acto que se reprocha a los demandantes se enmarcaba en el ámbito de una de estas puestas en escena provocadoras que se utilizan cada vez más para llamar la atención de los medios de comunicación y que, a sus ojos, no van más allá de un recurso a una cierta dosis de provocación permitida para la transmisión de un mensaje crítico desde la perspectiva de la libertad de expresión (asunto Mamère c. Francia, § 25).

Es un claro ejemplo de transversalidad de los derechos fundamentales que demuestra que no sólo importa cuando nos encontramos en el aula explicando el derecho fundamental a la libertad de expresión sino también cuando pensamos en nuestra forma de gobierno y en la protección que merecen la instituciones en un mundo tan convulso y tan posmoderno como el que nos está tocando vivir en pleno siglo XXI. ${ }^{11}$

\subsection{Cortes Generales}

Otro tanto se puede decir del Parlamento, institución esencial de toda democracia que se precie. La regulación que la Constitución haga del Parlamento es cuestión de cada Estado y tarea de cada Constitución. Además, en el ámbito parlamentario es especialmente importante el principio de autonomía parlamentaria, que ya de por sí suele implicar un amplio margen para que la Cámara se autorregule como mejor estime, fundamentalmente a través del Reglamento parlamentario. Así que, en principio, el TEDH nada tiene que decir sobre estos aspectos, salvo que se lesione algún derecho de los protegidos en el Convenio.

\footnotetext{
${ }^{11}$ Un comentario crítico puede verse en BILBAO UBILLOS, J.M"a; "La STEDH de 13 de marzo de 2018 en el asunto Stern Taulats y Roura Capellera contra España: la crónica de una condena anunciada", Revista General de Derecho Constitucional, $\mathrm{n}^{\circ}$ 28, 2018, pp. 1-29; y PRESNO LINERA, M.Á; "Crónica de una condena anunciada: el Asunto Stern Taulats y Roura Capellera c. España sobre la quema de fotos del Rey", Teoría y Realidad Constitucional n ${ }^{\circ}$ 42, 2018, pp. 539-549.
} 
Precisamente eso es lo que sucede en el asunto Karacsony y otros c. Hungría (STEDH 17/5/2016), donde una multa a unos parlamentarios de la oposición que manifestaron sus discrepancias con megáfonos, tanto en diferentes momentos del debate parlamentario como en diferentes momentos de las votaciones, consideró que atentaba contra el artículo 10 CEDH. ${ }^{12}$ Y eso porque la norma parlamentaria no les permitió defenderse en tiempo y en forma de la sanción impuesta. La sentencia no se dicta en el vacío, porque hay otros casos similares antes, como por ejemplo, mutatis mutandis, el asunto Hoon c. Reino Unido (2014), donde la sanción a un diputado que no dispone de garantías procedimentales para defenderse de medidas disciplinarias implica que aquél llegase a Estrasburgo, aunque este inadmite a trámite por que los derechos del art. 6, 8, y 13 no tienen suficiente base legal ratione materia. Cambiando las circunstancias que deban cambiarse, algo muy parecido puede decirse que sucedió en torno al asunto G.K c. Bélgica (2019), donde el Tribunal recuerda que al parlamentario no se le puede dejar huérfano de garantías procedimentales por más que sea el Parlamento quien decir abrir un procedimiento cuasi disciplinario conducente a la sanción de un diputado, figura protegida a nivel constitucional. ${ }^{13}$

Por último, no podemos olvidar cómo influyen las sentencias-piloto del TEDH en la tarea legislativa de los Parlamentos. En tanto que el Tribunal exige al país en cuestión que adopte "todas las medidas necesarias, incluso legislativas" para paliar las deficiencias estructurales que dieron lugar a la resolución piloto, está fuera de toda duda que su acervo jurisprudencial también afecta a una tarea nuclear del legislativo, como es precisamente la de legislar. Esto ha sido especialmente visible en las reformas legales que han introducido los países objeto de estos procedimientos, por dilaciones excesivas en sus procesos judiciales internos, tales como Alemania (asunto Rumpf, 2010); Grecia (asunto Athanasiou, 2010); y diversos casos relacionados con Bulgaria, Turquía, Hungría y Polonia. Uno de ellos fue el asunto Hirst (2) c. Reino Unido (2005), donde el TEDH establece que la legislación británica no se atiene al Convenio en tanto que establece una prohibición de voto sin límite para todo condenado a prisión, doctrina que ha repetido para situaciones análogas en países del Convenio como, sin ir más lejos, ha sucedido respecto a Rumanía en el asunto Branduse (2015).

\subsection{Gobierno}

Los Ejecutivos de las democracias constitucionales suelen tener conferidos los poderes que podríamos decir de mayor importancia en el día a día de las personas. Es el órgano más ágil y que mejor puede atender las demandas sociales de todo orden. Sobre los Gobiernos, al igual que razonábamos respecto de la Jefatura del Estado o del Parlamento, el TEDH en principio no es competente, salvo que la actuación (o inactuación: ahí está la doctrina de las obligaciones positivas, cada vez más aplicadas por la jurisdicción de Estrasburgo) del Gobierno lesione algún derecho fundamental. Obligaciones positivas, sobre todo en el marco de los artículos 2 y $3 \mathrm{CEDH}$, aunque no sólo. Esto debe ser resaltado.

Pero también aquí se atisba algún matiz. Por ejemplo, esos casos donde las autoridades nacionales gubernamentales debieron investigar las denuncias que se produjeron respecto a la limpieza de las elecciones y tales investigaciones no se llevaron a cabo condujeron al Tribunal Europeo de Derechos Humanos a declarar lesionado el derecho a unas elecciones

\footnotetext{
12 Sobre la misma véase MARTÍ SÁNCHEZ, S; "Los derroteros de la disciplina parlamentaria. Breve comentario a la sentencia del Tribunal Europeo de Derechos Humanos "Karácsony y otros c. Hungría" (17 de mayo de 2016)", Revista Española de Derecho Constitucional, no 113, 2018, pp. 313-326.

13 Vid. GARROTE DE MARCOS, Ma; "Un paso más en contra de la "autotutela parlamentaria". Comentario a la Sentencia del Tribunal Europeo de Derechos Humanos GK c. Bélgica, de 21 de mayo de 2019”, Revista de las Cortes Generales, n 108, 2020, pp. 469-482.
} 
libres reconocido en el artículo 3 del Protocolo 1 del Convenio (asunto Davydov y otros $c$. Rusia, STEDH de 30/5/2017).

Otro matiz viene del origen de estas eventuales lesiones, dado que suele ser el poder ejecutivo el otro gran pilar, además del legislativo, sobre el que descansa implementar las acciones requeridas para paliar y erradicar las deficiencias estructurales señaladas en las sentencias piloto. Valgan como ejemplo la restitución de propiedades en Polonia, a partir del conocido asunto Broniowski (el abono de las indemnizaciones estipuladas por ley ante expropiaciones ilícitas desde el punto de vista convencional, acaecidas en Albania, Rumanía, Bosnia, Croacia, Serbia y Eslovenia). Lo mismo cabe decir para el caso de transfusiones de sangre contaminadas, como sucedió en Italia; o la regularización de las inscripciones registrales, tal y como señaló hace no mucho el TEDH respecto de Eslovenia; tampoco quedan fuera del perímetro convencional el pago de deudas contraídas por las administraciones públicas de rigor, como estableció el TEDH en el caso Ivanov c. Ucrania, de 2009); o del abono de diferentes cantidades, en dinero o en especie, en Rusia (desde viviendas sociales asignadas pero no ejecutadas hasta documentos administrativos, pasando por un coches para minusválidos).

Uno de los ejemplos paradigmáticos del Gobierno tiene mucho que decir: la gestión de las prisiones y las condiciones materiales que se dan en ellas. Aquí son varias las sentencias piloto que los diferentes Gobiernos (también Parlamentos) deben acometer. Desde Ananyev c. Rusia (2012), se han dictado algunas sobre masificación reclusa, como Torregiani y otros c. Italia (2013), o Rezmives c. Rumanía (2017); también se han cuestionado diversas condiciones penitenciarias en asuntos como Neshkov c. Bulgaria (2015); o Varga y otros c. Hungría (2015). En ese sentido, W.D. c. Bélgica (2016) fue pionera, puesto que, mediante el recurso a la técnica de la sentencia piloto, entendió el TEDH que el artículo 3 obliga a los Estados miembro a proveer una correcta atención psiquiátrica a los presos con enfermedades mentales, so pena de incurrir en quiebra del Convenio. ${ }^{14}$

\subsection{Poder Judicial}

Entendido en su sentido más amplio, incluimos aquí también la jurisdicción de los tribunales constitucionales. Aunque podríamos llamar la atención sobre muchas cuestiones -no en vano, el artículo 6 del Convenio es sobre el que mas sentencias se dicta y donde más condenas se producen- nos interesa resaltar ahora tres.

La primera es que la protección de algunos derechos convencionales sirve para proteger también la propia esencia y organización del poder judicial, mediante el respeto al rule of law. Eso creo que es una de las posibles lecturas que se extraen del caso Baka c. Hungría (2016), donde el TEDH entiende vulnerados los derechos reconocidos en los artículos 6 y $10 \mathrm{CEDH}$. El Gobierno procedió a cesar al presidente del TS húngaro por unas declaraciones donde este opinaba sobre las reformas legales respecto a la judicatura, cese que se produjo antes de que expirase el mandato legal.

\footnotetext{
${ }^{14}$ Hemos podido decir algo sobre el diálogo que entablan los dos órganos de protección de los valores recogidos en el artículo 3 CEDH en ÁLVAREZ RODRÍGUEZ, I; Diálogos metajudiciales en Estrasburgo. El Tribunal Europeo de Derechos Humanos y el Comité de Prevención de la Tortura, Aranzadi, Cizur Menor, 2021.; y en ÁLVAREZ RODRÍGUEZ, I; Sobre la prevención de la tortura, Servicio de Publicaciones de la Facultad de Derecho de la Universidad Complutense de Madrid, Madrid, 2020. Véase también TURTURRO PÉREZ DE LOS COBOS, S; "Las sentencias piloto como mecanismo de integración europea en materia penitenciaria". En PÉREZ MIRAS, A (dir.); TERUEL LOZANO, G (dir.); RAFFIOTTA, E (dir.); IADICCO, M (dir.); Setenta años de Constitución Italiana y cuarenta años de Constitución Española, Vol. 2, 2020, pp. 119-132.
} 
La segunda es que el TEDH ayuda al cumplimiento de las resoluciones jurisdiccionales internas. Esa es otra lectura posible del asunto Sahin Alpay c. Turquía (2018), donde el TEDH establece que se ha vulnerado el derecho a no ser detenido de forma ilegal. Los acontecimientos tuvieron lugar a raíz del golpe de Estado en Turquía el 15 de julio de 2016 y la declaración del estado de emergencia. Sahin Alpay era un periodista crítico para con el Gobierno turco que es detenido y encerrado. Recurrida la detención, llegando hasta el Tribunal Constitucional, este reconoció que se habían vulnerado sus derechos y que debían ponerle en libertad. El tribunal de instancia que debía ejecutar el mandato constitucional se negó y el periodista acudió en amparo internacional, concedido por el TEDH.

La tercera es la creación de la Red de Tribunales Superiores, bajo los auspicios del TEDH. Mediante la misma se produce un fluido intercambio de información entre el tribunal de Estrasburgo y los tribunales nacionales que integran la red. Tienen a los efectos una intranet de acceso restringido, y las partes se comprometen a compartir la información de buena fe y sin causar daños en su manejo y/o diseminación (sin compartir información confidencial ni secreta). Tanto nuestro Tribunal Supremo como nuestro Tribunal Constitucional forman parte de la misma.

\section{Constitución y Economía y Hacienda.}

Aunque las materias relacionadas con la economía y hacienda forma parte de ese hardpower en el marco de las relaciones internacionales -en el lenguaje del TEDH: gozan de un amplio margen de apreciación nacional- lo cierto y verdad es que en las últimas décadas ese hard-power se ha ido trasvasando a instituciones internacionales tales como la Unión Europea, el Banco Central Europeo, o el Fondo Monetario Internacional. En principio, el Consejo de Europa no tiene mucho que decir en estas materias, toda vez que se creó con la idea de consolidar la democracia, los derechos humanos y el Estado de Derecho (pobre de aquel que piense que la democracia no se ve afectada por la economía).

En los últimos años esta afirmación se ha visto sacudida por cierta jurisprudencia de Estrasburgo (de impacto muy limitado como ahora se verá). El TEDH ha tenido que conocer de diversas medidas de austeridad adoptadas por otros tantos Estados miembro, ante demandas individuales (de personas físicas, pero también de personas jurídicas en algunos casos) que alegaban la vulneración de diferentes derechos protegidos en el Convenio. Aunque varias de esas demandas fueron inadmitidas a trámite (recorte de pensiones públicas en Portugal y en Italia, funcionaria lituana que sufre un recorte del 15\% en el salario; algunas empresas holandesas que sufren la disminución en sus ganancias derivadas de decisiones públicas...).

En el caso Valkov y otros c. Bulgaria (2011), una serie de jubilados alega que el recorte en sus pensiones atentaba contra el art. 1-Pr.1, que reconoce la protección de la propiedad. El TEDH entra a conocer pero no aprecia vulneración del precepto. Según su criterio esta medida era proporcionada, razonable y no discriminatoria. Una cosa parecida sucede en el caso Koufaki y ADEDY c. Grecia (2013). Un funcionario griego, Sr. Koufaki, vio recortado su sueldo de 2.435 a 1.885 euros; otros dos demandantes vieron cómo sus pagas 12 y 13 desaparecieron (aunque fueron compensadas con un bonus). Todo ello derivaba de los profundos recortes del gobierno griego. Según el TEDH, estos entraron dentro del margen de apreciación nacional y no observa vulnerado el precepto. Criterio muy similar se aprecia en el asunto Mamatas y otros c. Grecia (2016), donde la reducción de deuda pública perjudicó a quienes llegaron a Estrasburgo, viéndose obligados a cambiar sus bonos por otros de menor valor. Entienden los litigantes vulnerado el art. 1-Pr-1, pero el TEDH entiende que la intervención pública busca un interés público justificado, como preservar la economía y el bienestar griegos, y no condena al Estado. 
En cambio, en el asunto N.K.M c. Hungría (2013), una reforma legal que entró en vigor sólo 10 meses antes de que se despidiese a la demandante, que venía a recortar hasta el 98\% de las indemnizaciones por despido se consideró una medida desproporcionada que lesiona el artículo 1-Protocolo 1. También existió un pronunciamiento parcialmente favorable en el asunto McDonald c. Reino Unido (2014), donde el TEDH declaró contrario al derecho a la vida privada del art. $8 \mathrm{CEDH}$ el recorte en la asistencia sanitaria de una persona impedida y la sustitución de un asistente nocturno por unos pañales para la incontinencia ( $\sin$ ser incontinente), lo cual atenta contra su dignidad. Intentando ser diplomático, el TEDH estima esa violación hasta el 4 de noviembre de 2009, fecha en la cual las medidas que se pusieron por parte de las autoridades nacionales ya entraban dentro del margen de apreciación nacional, y eran proporcionadas porque buscaban el bienestar de otros usuarios.

\section{Constitución y organización territorial del Estado.}

Otro aspecto que suele ser de uso y disfrute de los Estados nacionales es la potestad de determinar qué tipo de organización territorial se dan. Aunque los vientos que soplan en las democracias constitucionales del Consejo de Europa después de la II Guerra Mundial han sido descentralizadores, también tenemos modelos más centralistas (Francia, países del Este). Ninguno de ellos aparece prejuzgado o exigido por las normas convencionales. Así que tampoco en este ámbito parece que el TEDH haya podido decir mucho.

No obstante, debemos recordar que cuando la junta de coroneles griega dio un golpe de Estado y declaró derogado el Convenio, haciendo uso del artículo 15 del mismo, en el año 1967, Suecia, Noruega, Dinamarca y Holanda denunciaron ante la Comisión que dicha derogación no se atenía a la legalidad convencional más elemental. Y así lo estableció la Comisión, en una Decisión de 1969, porque a juicio de esta no quedaba justificada la situación de emergencia que ponía en riesgo la vida de la nación como supuesto de hecho necesario para proceder del modo que aquellos deseaban o necesitaban. No alcanzamos a ver qué medida podría afectar más a todo un país, a territorio nacional, que tomar la decisión de que el Convenio deje de operar en la realidad de millones de vidas. ${ }^{15}$

Algo similar sucedió con la lucha antiterrorista por parte del Reino Unido contra el IRA, con diferentes casos que llegaron al conocimiento de la Comisión y del Tribunal (asuntos Lawless; e Irlanda c. Reino Unido) llegando a derogar el Convenio en Irlanda del Norte -esto es, afectando a una parte del suelo británico-. Tal cosa fue precisamente lo que aconteció en el asunto Brannigan y McBride c. Reino Unido; en su STEDH de 26 de mayo de 1993 el Tribunal llegó a la convicción de que en este caso sí se daba el riesgo vital para la nación y, por ende, la suspensión convencional estaba amparada, legalmente hablando.

Otro país que ha tenido también su cuota de protagonismo ha sido Turquía. Y debemos comenzar destacando la doctrina Loizidou, en una resolución dictada por la Gran Sala en el año 1995, donde la zona norte de Chipre estaba bajo mando militar turco. A la demandante no se la dejó entrar varias veces a sus propiedades. Entendió que tal extremo vulneraba el artículo 1 Pr- 1 y planteó demanda ante Estrasburgo. Lo interesante de esta sentencia es que extiende el concepto "jurisdicción" del artículo $1 \mathrm{CEDH}$, para decir que este no sólo abarca el territorio nacional de los Estados miembro, sino que llega a lugares controlados por sus fuerzas armadas del país en cuestión (independientemente de que esa ocupación sea legal o ilegal). La consecuencia directa de esto es que el Estado miembro

\footnotetext{
${ }^{15}$ Vid. ROCA FERNÁNDEZ, Ma; "La suspensión del Convenio Europeo de Derechos Humanos desde el Derecho español. Procedimiento y Control”, Revista Española de Derecho Europeo, n 72, 2019, pp. 4371.
} 
"invasor" debe garantizar los derechos y libertades del Convenio a todas las personas que se hallen ahí. De ahí que declare vulnerado el artículo 1 Pr-1.

Relacionado con esta situación, no puede olvidarse la situación tan precaria en la que quedan los territorios donde se suceden conflictos bélicos. El TEDH también ha dictado alguna sentencia en estas situaciones. Me refiero al litigio histórico entre Chipre y Turquía. En 1983, Turquía declaró un territorio hasta ese momento chipriota, en el norte, la "República Turca del Norte de Chipre". En el asunto Chipre c. Turquía (STEDH de 10/5/2001), Chipre denuncia ante el Tribunal las operaciones militares que los turcos desarrollaban en dichos territorios. Turquía alegaba que ahí había un Estado independiente y por ello, no sometido a la jurisdicción del Convenio (ni del Tribunal). El Tribunal hace caso omiso de este argumento y entiende que lo sucedido cae bajo jurisdicción turca y establece hasta 14 (han oido bien, 14) vulneraciones del Convenio. La situación de esos territorios condujo a diversas condenas adicionales a Turquía, por los desmanes con los que se condujo por la zona. En el caso Varnava y otros c. Turquía (2009), el TEDH entendió vulnerados los articulo 2, 3, y 5, por la desaparición de nueve chipriotas a manos de las fuerzas turcas; o el caso Andreou c. Turquía (2009), donde sentencia la lesión del artículo $2 \mathrm{CEDH}$ por disparar a un ciudadano británico que estaba en territorio chipriota bajo mandato de la ONU.

Otro caso interesante es el asunto Aksoy c. Turquía (STEDH de 18/12/1996), donde las autoridades nacionales declaran en 1987 el estado de emergencia en 10 de las 11 provincias del sudeste. En una de ellas apresan al Sr. Aksoy, quien denuncia por detención ilegal. Turquía responde que en esa parte del territorio no opera el Convenio, tal y como notificó desde los años 90 Turquía, invocando el art. 15 del mismo. El Tribunal, sin cuestionar que son las autoridades nacionales las que en mejor posición están para valorar las circunstancias que conducen a esa declaración, no acaba de ver claro que eso impida la participación judicial en la detención de las personas sospechosas de terrorismo. La incomunicación de hasta 14 días del Sr. Aksoy, sin intervención judicial de ningún tipo, atentó al Convenio. Lo cual viene a significar que se impuso a la declaración de emergencia y entró a conocer de lo sucedido en una situación que en principio no era de su competencia.

El mismo país vio como sucedió algo parecido, aunque en realidad distinto: se produce la detención policial de tres miembros del Parlamento en Ankara pero el Tribunal constata que Ankara no formaba parte del territorio afectado por la declaración del estado de emergencia, por lo que regían las garantías del Convenio; y en concreto para el caso, el artículo $5 \mathrm{CEDH}$, que declara vulnerado (asunto Sakik y otros c. Turquía, 1997). El Tribunal afecta de alguna manera a la organización territorial turca, cuando recuerda a sus autoridades que los efectos de la declaración de emergencia no pueden ser extendidos a territorios que originalmente no figuran explícitamente en la notificación de la declaración.

También puede y debe decirse algo sobre el conflicto Nagorno-Karabakh. Esta era una provincia autónoma de la república socialista soviética de Azerbaiyán. Armenia la reclama como suya cuando se produce la caída del régimen. En el año 1992 el territorio se declara independiente, pero no obtiene el reconocimiento de ningún Estado de la comunidad internacional. Se desata una guerra que dura hasta el año 1994. La OSCE acaba mediando en el conflicto, pero no hay acuerdo político respecto a la zona. Y en ese contexto llegaron algunos casos ventilados por el TEDH que dieron lugar a ciertas reacciones adversas desde el ámbito político de los territorios afectados.

En el asunto Chiragov y otros c. Armenia (STEDH de 2015), la Gran Sala ventila el caso donde 6 azerbaiyanos tuvieron que abandonar en 1992 sus casas y tierras de Lachin debido al conflicto. El TEDH confirma que Armenia ejercía el control efectivo sobre el 
territorio de Nagorno-Karabkah y que tenía jurisdicción sobre Lachin. Al no dejar que accedieran a la zona por seguridad no hicieron mal, pero tampoco ofrecieron un remedio compensatorio a los afectados. Eso fue bastante para que el TEDH dictase la violación del artículo 1 Pr-1, del artículo 8 y del artículo 13 del Convenio.

Del mismo conflicto nació el asunto Sargsyan c. Azerbayán (STEDH de 2015), también dictada por la Gran Sala. Un refugiado armenio tiene el mismo problema que el anterior, ahora en la región de Shahumyan, en Azerbayán. No se le deja volver a su pueblo y, por ende, no puede acceder a sus propiedades. Este fue el primer caso donde el Tribunal tuvo que decidir una demanda contra un estado que ha perdido el control de parte de su territorio debido a la guerra y posterior ocupación pero a la vez era responsable de rechazar a personas desplazadas del acceso a sus propiedades. Se unió una mayor carga dramática al asunto porque el demandante, interpuesta la demanda en Estrasburgo, fallece. Los hijos le suceden en el litigio y el TEDH declara, al igual que en el caso anterior, vulneración del artículo 1 del Protocolo 1, del artículo 8 y del artículo 13 del Convenio.

Por finalizar con la aplicación extraterritorial derivada de situaciones bélicas, tenemos una serie de sentencias que tienen que ver con la guerra de Irak más reciente (2003). Algunos casos ventilados por el TEDH no sólo admiten a trámite lo que allí sucedió, sino que declaran lesionados los artículos 3, 13, y 34 del Convenio (asunto Al-Saadoon y Mufdhi c. Reino Unido, 2010) o el artículo 2 (asunto Al-Skeini y otros c. Reino Unido, 2011); o el artículo 5 (asunto Al-Jedda c. Reino Unido, 2011). En otros, aun admitiendo a trámite casos donde el Estado parte alegaba expresamente que el Convenio no regía esas situaciones, no declaró vulnerado precepto alguno (por ejemplo, asunto Hassan c. Reino Unido, 2014), pero sí en otros (asunto Jaloud c. Holanda, 2014).

\section{Conclusiones.}

Este trabajo arroja dos conclusiones. Una que podríamos denominar sustantiva y otra de corte formal. La conclusión sustantiva versa sobre la hipótesis que hemos manejado como hilo conductor del presente texto. Así, hemos conseguido demostrar que existe algo a lo que podemos denominar democracia convencional y sus exigencias se basan en el cumplimiento una serie de requisitos mínimos a cumplir por todos los Estados miembros en su relación con el Convenio Europeo de Derechos Humanos. Tal democracia se basa en el respeto de los derechos humanos que este reconoce y que interpreta y actualiza el Tribunal Europeo de Derechos Humanos. Al hacerlo, sus resoluciones no sólo imparten justicia en el caso concreto, sino que afectan, siquiera tangencialmente, al ordenamiento constitucional en cuanto distribución institucionalizada del poder.

La conclusión formal se deriva de la anterior. Debido a los hallazgos resultantes de la presente investigación, cuando enseñamos en las aulas el Derecho Constitucional actual ya no podemos quedarnos en "actualizar" nuestro catálogo de derechos fundamentales en base a la literalidad constitucional y/o convencional y en la interpretación que los altos tribunales hagan de los mismos, sino que debemos explorar cómo afecta y en qué medida podría seguir afectando a nuestras instituciones y órganos estatales la interpretación que de tales derechos se hacen. Es muy probable que aspectos nucleares de las democracias constitucionales que enseñamos en las aulas tales como el sistema electoral y el rol de los partidos políticos, la organización y régimen jurídico de los poderes e instituciones estatales o, por seguir con el ejemplo, la organización territorial así como las diversas cuestiones relacionadas con la Economía y Hacienda ya no puedan ni deban abordarse obviando la influencia que los derechos fundamentales y su interpretación avanzada despliegan en el interior de todas ellas. Es así como se manifiesta la expansión y crecimiento sin par de un sistema que comenzó constituyendo un control muy excepcional 
de las actuaciones de los Estados hasta acabar por convertirse en unos de los guardianes de la democracia a nivel europeo.

7. Bibliografía.

- ÁLVAREZ RODRÍGUEZ, I; Diálogos metajudiciales en Estrasburgo. El Tribunal Europeo de Derechos Humanos y el Comité de Prevención de la Tortura, Aranzadi, Cizur Menor, 2021.

- ÁlVAREZ RODRÍGUEZ, I; Sobre la prevención de la tortura, Servicio de Publicaciones de la Facultad de Derecho de la Universidad Complutense de Madrid, Madrid, 2020.

- ÁllareZ RODRÍGUEZ, I; Brechas Convencionales en España. Un reto constitucional del siglo XXI, Aranzadi, Cizur Menor, 2020.

- BILBAO UBILlOS, J.Ma; "La STEDH de 13 de marzo de 2018 en el asunto Stern Taulats y Roura Capellera contra España: la crónica de una condena anunciada", Revista General de Derecho Constitucional, n 28, 2018.

- CASADEVAlL, J; El Tribunal de Estrasburgo. Una Inmersión Rápida, Tibidabo Ediciones, Barcelona, 2019.

- ELÓSEGUI ITXASO, M; MORTE GÓMEZ, C; MENGUAL I MALLOL, A.M; y CANO PALOMARES, G (coords); Construyendo los derechos humanos en Estrasburgo. El Tribunal Europeo de Derechos Humanos y el Consejo de Europa, Tirant lo Blanch, Valencia, 2020.

- ELÓSEGUI ITXASO, Ma: "El principio de proporcionalidad, la incitación al odio y la libertad de expresión en la reciente Jurisprudencia del Tribunal Europeo de Derechos Humanos: los Casos Stomakhin c. Rusia, Williamson c. Alemania y Pastörs c. Alemania", Revista General de Derecho Europeo, n'. 51, 2020.

- FERNÁNDEZ-MIRANDA, A; y C; Sistema electoral, partidos políticos y Parlamento, Colex, Madrid, 2008 (2 $2^{\text {a }}$ edición).

- FERRAJOLI, L; Constitucionalismo más allá del Estado, Trotta, Madrid, 2018.

- FERRER MARTÍN DE VIDALES, C; “The European integration process. Its effects in the principle of separation of powers set up in Member State's Constitutions", Revista Universitaria Europea, $\mathrm{n}^{\mathrm{o}}$ 33, 2020.

- GARCÍA ROCA, J; La transformación constitucional del Convenio Europeo de Derechos Humanos, Aranzadi, Cizur Menor, 2019.

- GARROTE DE MARCOS, Ma; "Un paso más en contra de la "autotutela parlamentaria". Comentario a la Sentencia del Tribunal Europeo de Derechos Humanos GK c. Bélgica, de 21 de mayo de 2019", Revista de las Cortes Generales, $\mathrm{n}^{\mathrm{o}} 108,2020$.

- GARROTE DE MARCOS, $\mathrm{M}^{\mathrm{a}}$; El sistema electoral español. Memoria, balance y cambio, Marcial Pons, Madrid, 2020.

- LÓPEZ GUERRA, L; El Convenio Europeo de Derechos Humanos según la jurisprudencia del Tribunal de Estrasburgo, Tirant lo Blanch, Valencia, 2021.

- MARTÍ SÁNCHEZ, S; "Los derroteros de la disciplina parlamentaria. Breve comentario a la sentencia del Tribunal Europeo de Derechos Humanos "Karácsony y 
otros c. Hungría" (17 de mayo de 2016)", Revista Española de Derecho Constitucional, $\mathrm{n}^{\circ} 113,2018$.

- MATIA PORTILLA, F.J (dir): Problemas actuales sobre el control de los partidos políticos, Tirant lo Blanch, Valencia, 2016.

- MONTESINOS PADILLA, C; La tutela multinivel de los derechos desde una perspectiva jurídico-procesal, Tirant lo Blanch, Valencia, 2017.

- ORTEGA CARCELÉN, M; España en positivo, Servicio de Publicaciones de la Facultad de Derecho de la Universidad Complutense de Madrid, Madrid, 2018.

- PINTO DE ALBUQUERQUE, P; "The constitutionalisation of the legal order of the Council of Europe". En MOTOC, I; PINTO DE ALBUQUERQUE, P; y WOJTYCZEK, K (eds); New developments in constitutional law. Essays in honour of András Sajó, Eleven International Publishing, The Hague, The Netherlands, 2018.

- PRESNO LINERA, M.Á; “Crónica de una condena anunciada: el Asunto Stern Taulats y Roura Capellera c. España sobre la quema de fotos del Rey", Teoría y Realidad Constitucional $\mathrm{n}^{\circ}$ 42, 2018.

- ROCA FERNÁNDEZ, M.J; "Límites a la libertad de expresión de los políticos. Los casos Féret c. Bélgica y Perinçek c. Suiza”, Revista de Derecho Político, nº 109, 2020.

- ROCA FERNÁNDEZ, Ma; "La suspensión del Convenio Europeo de Derechos Humanos desde el Derecho español. Procedimiento y Control", Revista Española de Derecho Europeo, $\mathrm{n}^{\circ}$ 72, 2019.

- TURTURRO PÉREZ DE LOS COBOS, S; "Las sentencias piloto como mecanismo de integración europea en materia penitenciaria". En PÉREZ MIRAS, A (dir.); TERUEL LOZANO, G (dir.); RAFFIOTTA, E (dir.); IADICCO, M ${ }^{\mathrm{a}}$ (dir.); Setenta años de Constitución Italiana y cuarenta años de Constitución Española, Vol. 2, 2020.

- VVAA; “El Tribunal Europeo de Derechos Humanos", Teoría y Realidad Constitucional, $\mathrm{n}^{\circ}$ 42, 2018. 